Journal of Thermal Engineering, Vol. 5, No. 5, pp. 422-445, October, 2019

Yildiz Technical University Press, Istanbul, Turkey

\title{
NUMERICAL ANALYSIS OF FLAME CHARACTERISTICS AND STABILITY FOR CONICAL NOZZLE BURNER
}

\author{
Julanda Al-Mawali ${ }^{1}$, Sam M Dakka ${ }^{2}$ *
}

\begin{abstract}
The stability and the mean structure of methane partially premixed conical burner flames was investigated numerically using ANSYS Fluent. The study presents and discusses the stability curves of the partially premixed flame and maps the mean flame structure based on contours of mass fraction of $\mathrm{O}_{2}, \mathrm{CO}$ and temperature. From the data obtained, it can be concluded that both premixed and non-premixed flames are less stable than the partially premixed flames. An optimum level of partially premixing was found and the flames beyond this threshold were found to be less stable. This optimum level was found, when the ratio of the mixing length to the nozzle diameter is equal to 5. At this specific degree of partially premixing, the flame exhibited triple interaction reaction zones. It was found that with an increase of the angle of the cone of the burner, the air entrainment increases which, in turns breaks the stabilization core and hence cause a reduction in the flame stability limit. The main role of the cone is to provide a protection from the surrounding environment at early phase of the reaction near the jet exit where turbulence with high intensity was observed.
\end{abstract}

Keywords: Partially Premixed Flames, Flame Stability, Conical Burner, Aircraft Combustion Systems, Triple Reaction Zones, Mixing Length, Low Emissions

\section{INTRODUCTION}

Aircraft engines performance cycles are characterized by wide different ranges of operating conditions which implies that flame stability is crucial in maintaining continuous operation of the engine. And therefore, the design of combustion systems has shifted towards technologies that incorporated partially premixed flames combustion systems. Partially premixed flames offer the advantage of lean premixed flames in terms of emissions reduction [1] due to relatively lower flame temperature in addition to flame stability. Emission reduction is another important factor of such technologies to meet the stringent pollutant emission regulations [2]. Therefore, special consideration of burner design in terms of burner mixing length which will impact the degree of the partial flame premixing through the flame equivalence ratio and cone angle will have strong impact on flame stability and emissions which is the subject of this investigation of optimization of the burner by selecting the degree of partially premixed flames to maintain stability and lower NOx emissions.

The study is focused on the impact of level of flame premixing and the burner cone angle on the flame behavior and flame stability and emissions. The burner design used in this study is similar to a burner developed and reported elsewhere [3]. Figure 1 shows the schematic drawing of the burner used in this investigation. The burner has a simple geometry as it contains two concentric tubes with a cone at the exit of the outer tube. The air flows through the inner tube while the fuel flows through the outer tube. The fuel and the air start to mix at the inner tube exit and they keep mixing through the mixing length "L", which can be defined as the distance between the inner tube exit to the outer tube exit. During the numerical simulation, the premixing distance was varied from $0 \mathrm{~mm}$ to $70 \mathrm{~mm}$. When the premixing length is set at $\mathrm{L}=0$, the generated flames are called non-premixed or diffusion flames. As the mixing length increases, the level of premixing between the fuel and the air increases proportionally. When the mixing length is set to be short $(\mathrm{L} / \mathrm{D}<1.5)$, the generated flame is said to be partially premixed. With longer ' $\mathrm{L}$ ' the generated flame can reach fully premixed conditions. A number of conical nozzles with cone angles of $20^{\circ}, 25^{\circ}, 30^{\circ}, 35^{\circ}$ and

This paper was recommended for publication in revised form by Regional Editor Jovana Radulovic

${ }^{1}$ Department of Engineering and Math, Sheffield Hallam University, Howard Street, Sheffield S1 1WB UK

${ }^{2}$ Department of Mechanical, Materials and Manufacturing Engineering, The University of Nottingham, University Park, Nottingham NG7 2RD, UK

*E-mail address: sdakka1@protonmail.com

Orcid id: 0000-0001-9225-761X

Manuscript Received 30 December 2018, Accepted 29 March 2019 
$40^{\circ}$, have been used during the present investigation. The height of the conical nozzle was kept at $53 \mathrm{~mm}$ for all cone angles.

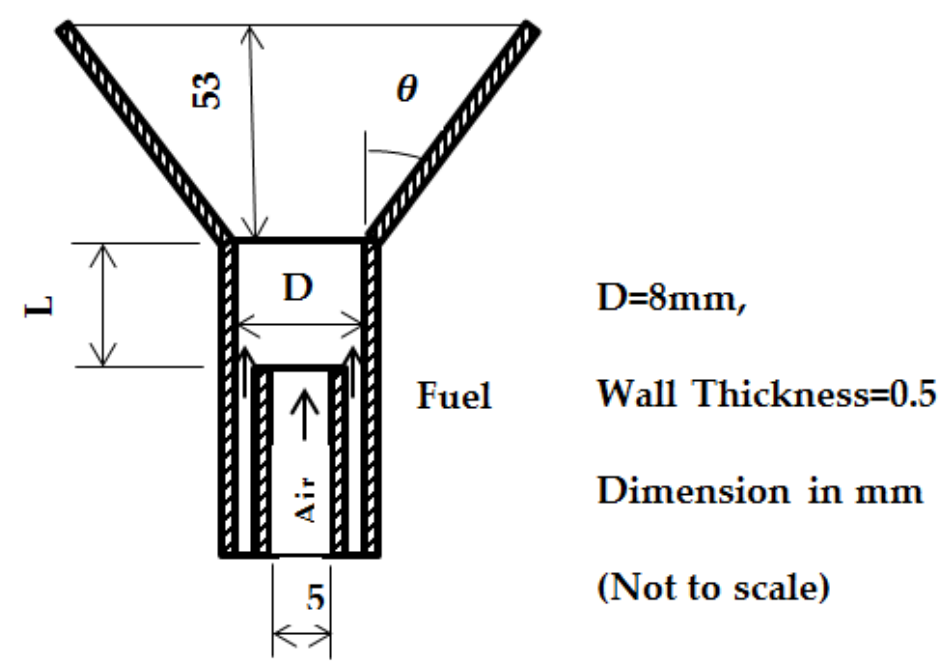

Figure 1. A schematic diagram of the burner [17]

The values of the jet velocity, equivalence ratio and the mixing length were controlled for each conical nozzle to study the flame stabilization of the burner. Based on the stability limits findings, several stable flames will be selected for different cone angle to conduct further detailed investigation.

For that, the radiative properties of the suspended particles and the media that contains those particles should be investigated deeply. As there are many particles in a particulate medium, the scattered photon from a particle may interact with those from other particles. This means, an incident beam can be scattered more than one time and they can be scattered again by the nearby particles $[7,8]$.

Stability is one essential feature of a good burner design. In general the burner stability is defined by maintaining a sustained flame while varying the fuel air mixture ratio, the flow speeds and the inlet temperature [4]. The current study is focused on the effect of fuel air mixing in sustaining the stability of the flames, but in general the stability of the burner will depend on a range of equivalence ratios that can sustain stable flames [5] which is bounded by two types of extinction, weak and rich extinction. The former occurs as a result of having too much fuel in the mixture whereas the latter occurs due to having too little fuel in the mixture. These two limits mainly rely on the mass flow rate of the fuel passing through the burner chamber with constant air flow rate. Numerical as well as experimental studies have demonstrated that the flame encounters sustaining problems at high velocities [6]. Thus, having high flow velocity flow could also lead the flame to blow off. Similarly, having low velocity flow could lead to flashback phenomena. There are several reasons which could cause the burner or combustors to blow off such as the use of lean fuel-air mixture or could be as a result of very strong combustion instabilities. For the burners to operate at low level of NOx, the burners tend to utilise a very lean mixture, which means that they have to operate close to their blow-off limits [7]. The phenomena of the blow off could lead to serious problems in combustors if reignition system suffers a failure to re-ignite the mixture, especially under extreme conditions such as low pressure and temperature at high altitudes.

A wide range of publications is available on measuring, correlating and calculating the blow-off limits [8]. There are also numerous and different hypotheses and physical models which were established to describe the phenomena of blow off. The characteristics of the blow off for a bluff-body were determined in terms of equivalence ratio as function of the jet velocity [8]. Determining the equivalence ratio of the flame blow off starts with establishment of the flame at stoichiometric conditions and then slowly decreasing the mass flow rate of the fuel until the flame blows-off. Such phenomena happens mainly when the available time for the fuel-air reaction is less than the required time to make enough heat to cause the fresh mixture to rise to its ignition temperature [9]. 
Suggestion was made [10] that the blow off phenomena occurs when the flame physically abandon the burner and blow out of the burner. This problem is also known as the static stability. Such problem occurs when the flame is not able to stay attached or anchored in the burner. Furthermore, increasing the jet velocity while keeping the equivalence ratio constant, caused the flame to blow off. Similarly, reducing the equivalence ratio to a certain value while keeping the jet velocity, caused the flame to blow off. Several References were found to relate the Damkohler Number, Da, with the chemical reaction and extinction [11]. These references had calculated the time of blow off using the Damkohler Number, which in turns, enabled them to calculate the blow off limits. The Damkohlar number, Da, can be simply defined as the ratio between the residence time ( $\boldsymbol{t}_{\text {res }}$ ) and the chemical kinetic time ( $\boldsymbol{t}_{\boldsymbol{c h e m}}$ ) [11]. Generally, the lean blow off is defined as the leanest fuel air mixture limit which allows the flame to propagate. The limit of flammability depends on several factors such as the chemical properties of the fuel-air mixture and the configuration of the burner. For the lean mixture, the blow off occurs when the velocity of unburnt mixture flow is higher than the flame speed [10]. At the present time, the phenomena of blow off are avoided by operating the burners or the combustors under large safety factor from the blow off limit. This means, operating the combustors with higher equivalence ratio (higher temperature) which in turns, leads to high level of NOx pollutions. To minimise the pollutants level of the combustors, the safety factor should be reduced to a minimum value by which the combustors can operate safely and efficiently. Recently, it has been demonstrated that the designers can monitor the blow off stability safety margins by using suitable analyses of the flame's optical signature and acoustics [12].

A study [13] was conducted on the "stabilization mechanism of highly stabilized partially premixed flames in concentric flow conical burner". The aim of the study was to investigate the stabilisation mechanism within the conical nozzle based on 2D measurements of the temperature field and flow field. Five different partially premixed flames were selected at equivalence ratio range between 2.5 and 5 and at Re number range between $8.3 * 10^{3}$ and $14.5^{*} 10^{3}$. A 3D PIV system was used in this study to obtain the turbulent flow field inner and outer of the conical nozzle. The obtained data shows that there is a recirculation zone at the near region inside the conical nozzle which suggests the existence of air entrainment along the wall of conical nozzle. The air stream resulting from the air entrainment is expected to be heated by the flame and therefore enhance the flame stability. Moreover, this study found the flow pattern inside the cone has a direct effect on the stabilization mechanism of the conical burner. It was also found that having conical nozzle attached to the burner improves the flame stability compared to the burner without the conical nozzle and this mainly due to the structure of the flow field inside the conical nozzle. Experimental PIV data showed the velocity vectors of flow inside the cone indicating the existence of a recirculation zone near the wall of the conical nozzle which is believed to improve the overall stability performance of the burner. As for the effect of the Equivalence ratio, this study found that there is a limited effect on the flow field structure formed inside the conical nozzle.

Another study [14] had conducted an experimental study to investigate the effect of the nozzle geometry and the mixing length on the stability and structure of the flame. The study had presented and discussed the stability curves of partially premixed flame and the maps of the mean flame structure which is based on measurements of the concentration of the $\mathrm{O}_{2}$ and $\mathrm{CO}$ and the temperature. From the data obtained from the experiment, it was observed that both premixed and non-premixed flames are less stable than the partially premixed flames and an optimum level of partially premixed was found to be at $\mathrm{L} / \mathrm{D}=5$ for the Conical Nozzle burner, and the flames beyond this level were found to be less stable. At this specific degree of partially premixing, the structure of the flame is likely to generate diffusion, lean and rich interacting reaction zones which lead to form triple flame structure. The obtained data also shows that the geometry of the conical burner has a great effect on the flame stability limits. It was found that with an increase of the angle of the cone, the air entrainment increases which, in turns breaks the stabilization core and hence cause a reduction in the flame stability limit. Regardless of the cone angle, the cone main role is to provide protection from the surrounding environment at the early phase of the reaction near the jet exit where high intensity turbulence is expected. Therefore, the study concluded that the burner with cone is considered to be more stable than that without cone.

Another study [3] showed the $\mathrm{CO}$ and $\mathrm{O}_{2}$ concentrations of different conical burner flames at different cone angles. The results illustrate and highlight the effect of the air entrainment on the flame structure as discussed earlier. 
A study [15] was conducted to investigate the effect of the premixing level on the local extinction and stabilization characteristics of the methane-air flames. Simultaneous OH-PLIF/PIV techniques and Large Eddy Simulation (LES) were used in this study. The partially premixing was generated in a burner with two concentric tubes, where the degree of the partially premixed flames was generated by controlling the length of the mixing chamber. The burner was mounted with a cone at the mixing chamber exit in order to stabilize the flames. The stability limit was obtained for different Reynolds number and level of partially premixing. This study found that the flames became more stable at low Re numbers when the mixing length decreases. For high Reynold numbers, it was found that there is an optimal mixing length at which the burner generates the most stable flames. To enhance the understanding of the stability behaviour, the OH PLIF images which were taken at equivalence ratio of 1.5 and at $\mathrm{L} / \mathrm{D}=5$ were analysed [15]. The findings showed that at low Reynold Number (4000), the OH radicals were observed to be in smooth and narrow zones (Laminar Flame type). As the Re number increased beyond 4000 and below 8000 the $\mathrm{OH}$ radicals were found to be distributed in wider zone. Furthermore, some discontinuity within this zone was observed and believed to indicate to local flame extinction. Increasing the Re number to 12000 and beyond causes the flame to blow out.

Another study [16] was carried to investigate the effect of fuel/air premixing degree on the in interaction between the flow field and Flame Kernel. The Partial premixing level and the jet velocity were the main parameters in this study. Five different velocities ranging between $10 \mathrm{~m} / \mathrm{s}$ and $20 \mathrm{~m} / \mathrm{s}$ and three degrees of partial premixing were chosen to be investigated in this study at constant equivalence ratio of 2 . This study used Planar Imaging Velocimetry (PIV) to take measurements of turbulent intensity and the mean flow field. Furthermore, the study had also conducted flame stability for the burner at different level of mixing, $\mathrm{L} / \mathrm{D}=2,4$ and 6 where $\mathrm{L}$ is the mixing length and $\mathrm{D}$ is the diameter of the outer tube. The obtained result for the stability study was plotted as jet velocity $(\mathrm{m} / \mathrm{s}) \mathrm{vs}$ the jet equivalence ratio. The stability limit was obtained by reducing the fuel mass flow rate till blow off, while the air is kept constant. It was found that level of partially premixed at $\mathrm{L} / \mathrm{D}=2$ provide the most stable flame.

All previous reviewed studies have demonstrated that the mixing length (L/D) has a significant effect on the stability limit of the flame. The experimental and numerical results of these studies show that at small values of mixing length $(\mathrm{L} / \mathrm{D})$, towards diffusion conditions $(\mathrm{L} / \mathrm{D}=0)$, the flames were observed to be less stable than those at higher mixing length where more air-fuel mixing is predicted. Moreover, these studies have shown that there is a specific point in the stability curve beyond which the flame is said to be less stable. Most of the reviewed studies have found that flames are most stable at mixing length ( $\mathrm{L} / \mathrm{D}=5)$.However, the study made by [16] found the mixing length of $(\mathrm{L} / \mathrm{D}=2)$ generates the most stable flames which does not agree with other reviewed studies made by [17] and [3]. The reason behind this disagreement is believed to be as a result of a turbulence generator disk utilised in one of the studies [16]. This generator was placed to increase the level of partial premixing for the same L/D since smaller value of the mixing length is required to generate the optimum conditions for the flame stability. Thus, from the previous works, it can be concluded that the partially premixed flames are considered to be more stable compared to the non-premixed and fully premixed. This can be explained as a result of mixing air and fuel prior to combustion chamber, leads to combustion of non-homogenous mixture which is likely to generate a structure of multi reaction zones, namely, diffusion, lean and rich [18]. Such structure occurs as a result of interaction of the rich pockets with the lean pockets in the flame. The reaction zones resulting from this interaction is likely to create triple flame structure which is believed to be able to survive at high turbulence intensities. Several studies have observed the triple flame structure in the partially premixed flames $[1,19,20]$.

The reviewed studies have also shown that the cone angle has a significant effect on flame stabiliy. Small angle generated more stable flames compared to that of large cones angles, and cone angle between 20-25 degrees were found to generate the most stable flames. This is believed to be due to air entrainment as it causes the stabilization core to squeeze and with a higher cone angle the stabilization core is expected to break, leading to flame extinction. 


\section{CAD MODELLING APPROACH}

The geometry of the Conical Nozzle burner can be modelled as $3 \mathrm{~d}, 2 \mathrm{~d}$ or axisymmetric. Using the $3 \mathrm{~d}$ model of the whole burner will require a large number of mesh nodes and elements which will lead to high processing time and this also could have negative impact on the accuracy level of the numerical results due to the limitation of the computer processor capability. The processing time of any CFD problem is proportional to number of degrees of freedoms as shown in the following expression, Processing Time $\alpha \mathrm{n}^{2}$ [21]. The expression illustrates the relation between the number of degrees freedom (n) and the processing time. This means that when the whole geometry is used for simulation run, it will take a processing time of $n^{2}$, while the half of the geometry will take about 4 times lower $\left(n^{2}\right) / 4$ than that of the whole geometry. Since the present burner is believed to be symmetric, it was decided that the axisymmetric (2d) will be used as a modelling approach for the rest of the study. The main reason behind this selection is that the axisymmetric model will take lower processing time and will produce more accurate results. The other motivation for this selection is the mesh elements limitation by ANSYS to $(500,000)$ and the limitations in the processor capability of the university computers. Figure 2 and 3 shows the axisymmetric model and the 3D Model of the burner and the dimensions of the axisymmetric model of the conical burner respectively.

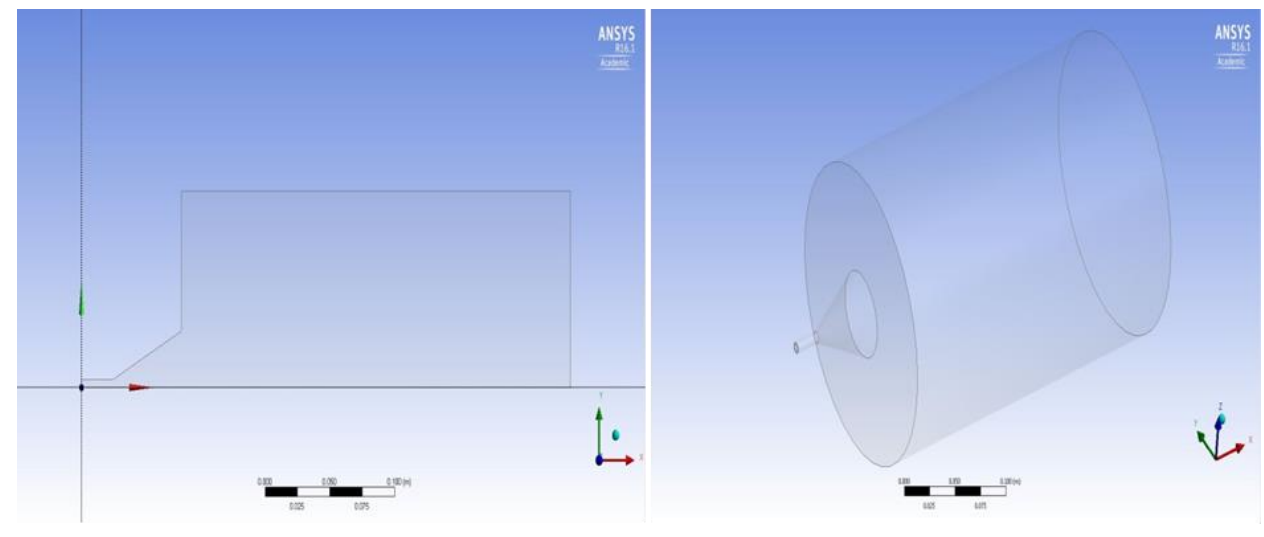

Figure 2. Axisymmetric model and 3D model of the burner respectively

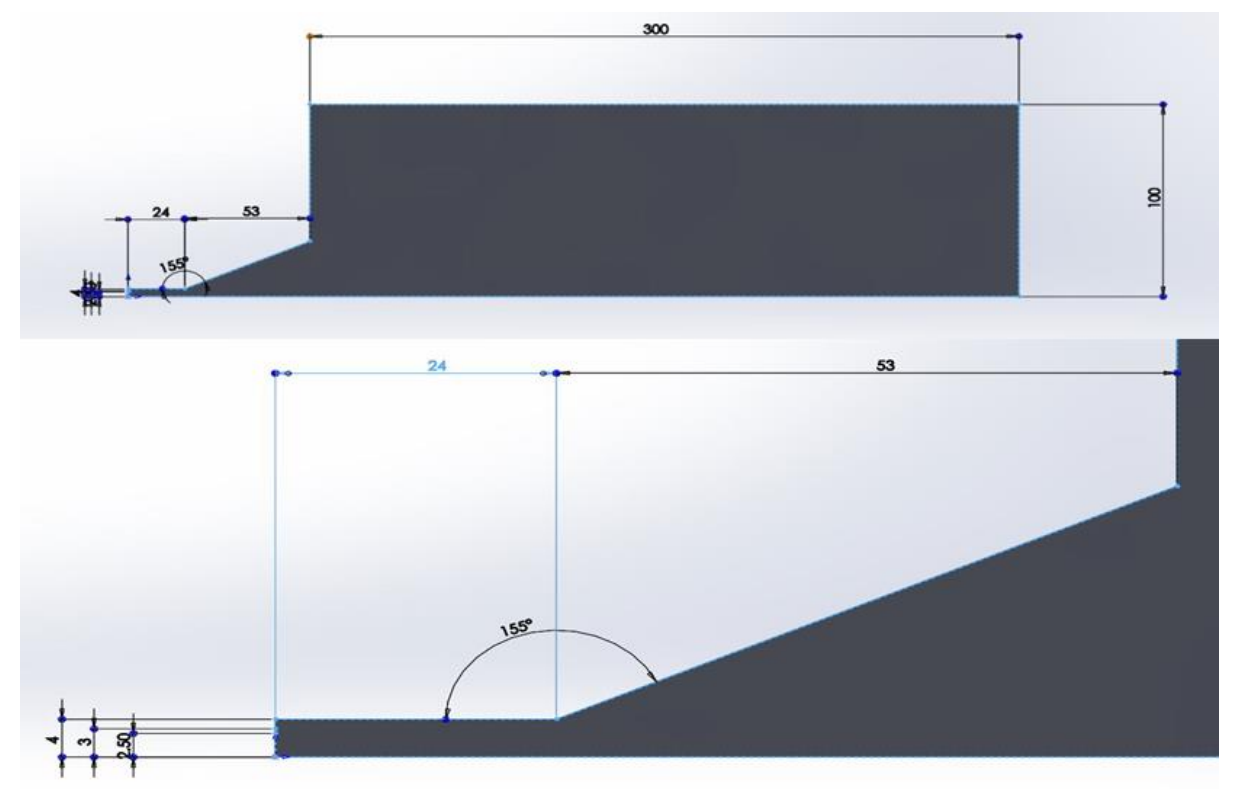

Figure 3. Dimensions of the axisymmetric model of the conical nozzle burner 


\section{Mesh Sensitivity Study}

The number of mesh elements or the mesh grid size is considered to be very essential in numerical simulations as the accuracy level of flow description depends mainly on the grid size. Therefore, developing or creating the ideal model which is able to fulfil the engineering solutions without using a very fine mesh size is one of the top challenges designers and engineers are encountering in the present time. As the mesh grid gets smaller (finer), it leads to a high computational cost as it uses a model that requires a very fine mesh such as the Direct Numerical Simulation (DNS). In comparison, as the mesh size gets larger (Coarser), it leads to low computational cost as it utilises models such as Reynolds Average Navier-Stokes (RANS) which result in very poor description of the simulated flow especially when simulating turbulent flow [22]. Thus, utilising the right mesh size is very significant.

In the present study, different mesh sizes were used in order to investigate the effect of the grid size on the level of accuracy of the numerical results and then selected the right grid size to be used throughout the study. The simulation was run for turbulent partially premixed flame using standard k-epsilon model for methane-air combustion at stoichiometric condition $(\Phi=1)$ at $300 \mathrm{k}$, ambient pressure. Reviewing the literature, it was found that the adiabatic flame temperature for the methane air combustion at stoichiometric condition is between 2240 to 2245 $\mathrm{K}[23,24]$.

This study conducted mesh sensitivity analysis by running the same boundary conditions at different numbers of elements and monitoring the Adiabatic Flame temperature of partially premixed flame at each run. It can be seen from the Figure 4 that the flame temperature changed by $27 \%$ from 2791 to 8426 elements number, while it only changed by $2.5 \%$ from 20582 to 72356 elements number. Thus, it can be concluded that the mesh convergence occurs between 20582 to 72356 elements number. Based on the mesh sensitivity study, the mesh with 20582 elements number was selected for rest of the study. The main reason behind this selection is that the mesh with 20582 would produce results with high level of accuracy and with minimum computing time. It was also found that the predicted flame temperature results at the selected mesh is close to what it was found in the literature, as shown in Figure 4.

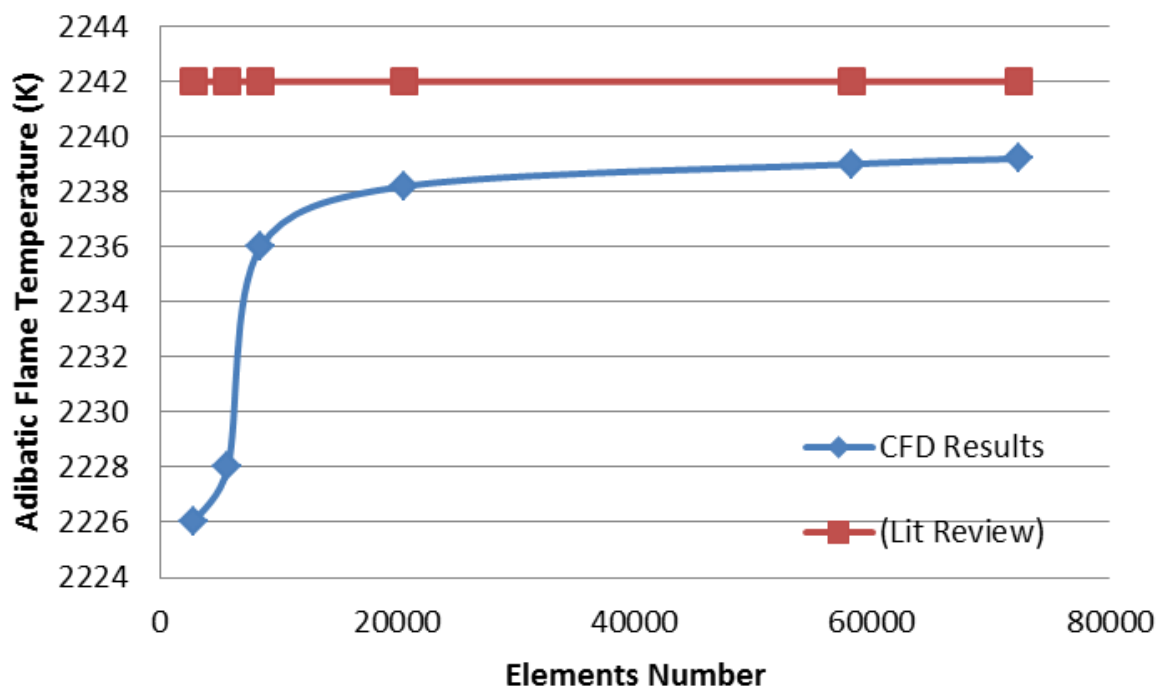

\section{Mesh Skewness}

Figure 4. Mesh sensitivity analysis

The skewness of the mesh is a good indicator of the mesh quality level. Table 1 shows the mesh quality measurements based on the mesh skewness recommended by ANSYS. For our selected mesh, the max skewness was found to be 0.438 , as shown in Figure 5.This means that the selected mesh is of very good quality based on the ANSYS measurement table. 
Table 1. Skewness mesh metrics spectrum

\begin{tabular}{|c|c|c|c|c|c|}
\hline Excellent & Very Good & Good & Acceptable & Bad & Unacceptable \\
\hline $0-0.25$ & $0.25-0.5$ & $0.5-0.8$ & $0.80-0.94$ & $0.95-0.97$ & $0.98-1.00$ \\
\hline
\end{tabular}

\begin{tabular}{|l|l|}
\hline Mesh Metric & Skewness \\
\hline$\square$ Min & $3.2535 \mathrm{e}-004$ \\
\hline$\square$ Max & 0.43877 \\
\hline$\square$ Average & $1.5638 \mathrm{e}-002$ \\
\hline$\square$ Standard Deviation & $1.8312 \mathrm{e}-002$ \\
\hline
\end{tabular}

Figure 5. Mesh skewness of the selected model

Figure 6 shows the final mesh that was used through the study. The edge sizing with bias and face sizing were used to generate a structured mesh. More refine mesh was created near the cone angle as string turbulence was expected at early stage of the flame.

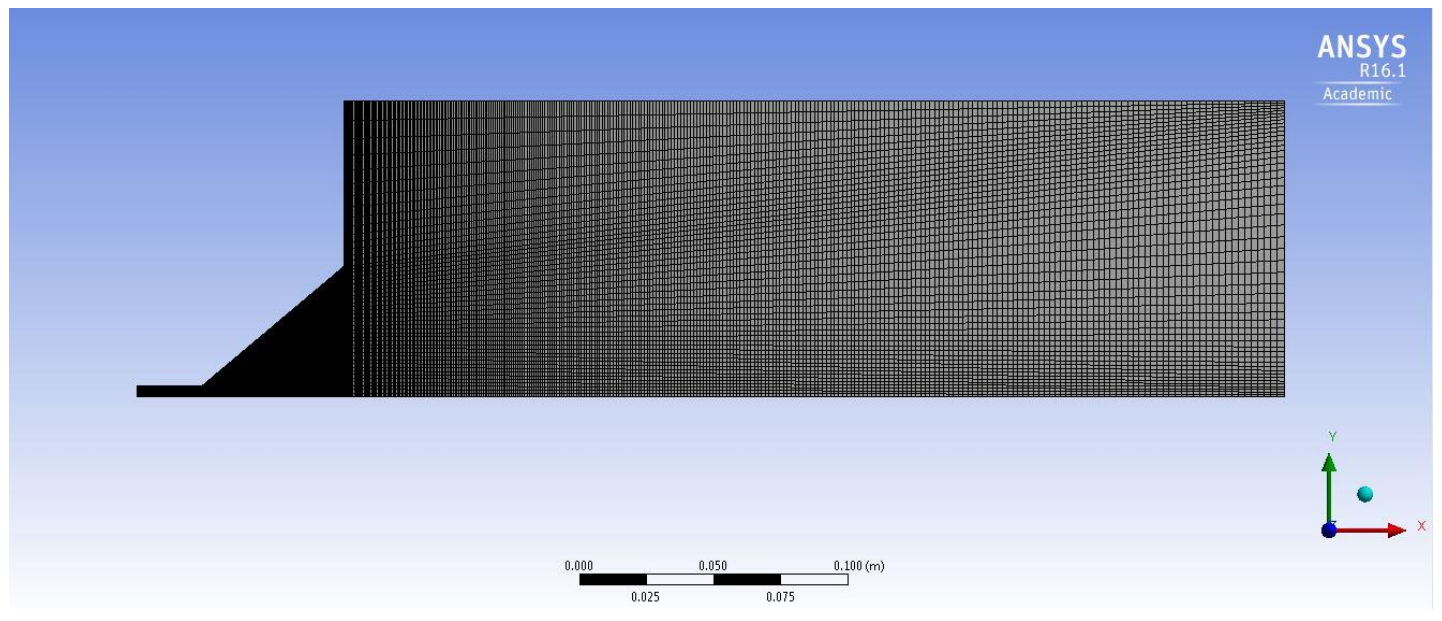

Figure 6. Structured mesh

When it comes to the mesh, it is also very essential to select the right size of the mesh near the wall in order to ensure a flow simulation with level of accuracy [25]. The $Y^{+}$value can be calculated to determine the right distance between the wall and the first node near the wall. The $Y^{+}$for the present burner was found to be 0.00029 . This value was then entered in the first layer thickness of the inflation. Table 2 illustrates final mesh details utilised in the simulation. 
Table 2. Final mesh details

\begin{tabular}{|c|c|c|}
\hline & Parameter & Value \\
\hline 1 & Nodes number & 29039 \\
\hline 2 & Elements number & 28303 \\
\hline 3 & Max Skewness & 0.442 \\
\hline 4 & Orthogonal Quality & 0.76 \\
\hline 5 & Mesh Method (1) & Edge sizing with bias \\
\hline 6 & Mesh Method (2) & Face Meshing \\
\hline 7 & $\mathrm{Y}^{+}$ & 0.00029 \\
\hline
\end{tabular}

\section{CFD Solver Set-up}

CFD Solver:

The methods used by the Computational Fluid Dynamic are usually categorised to two schemes:

- Pressure-based

- Density-based.

The pressure based method is considered to be the basis for most of the present commercial CFD codes which is also a very suitable to be used for the low Mach number and incompressible flows, while the density-based method is well-suited for the transonic and supersonic flow fields [22]. The pressure-based method uses the pressure correction and the momentum as its primary variables and it has two algorithms, namely, segregated solver, which is used to solve momentum and pressure in sequential manner, and Coupled solver which is used to solve for momentum and pressure in simultaneous manner. The density based method solves energy, momentum and continuity equations in form of vector and it also uses the equation of state to solve the pressure. This solver is able to utilise either explicit or implicit solution approach [26].

The pressure based solver can be used for wide range of flows from high Mach number compressible flows to low Mach number incompressible flow. This method requires less storage and also allows high flexibility during the solving procedure. On the other hand, the density-based method is applicable for the flow regimes where a strong coupling exists between momentum, density and energy [22]. Such solver is well-suited to be used for high Mach compressible flow with shock interactions and hypersonic flows. Since, the present study is directed to investigate low speed incompressible flows and have storage limitations; the pressure-based solver was selected for the current study. This study has also used the steady time over the transient as the former is considered to run faster as it ignores number of cross terms and higher order terms that deals with time. The transient simulation is also known to have higher requirements in terms of disk storage and CPU time [27] .Two dimensional space is selected to be axisymmetric as the model approach of the burner was selected earlier to be axisymmetric as explained in the modelling approach section. Table 3 illustrates the selected parameters for the simulation set-up. 
Table 3. Simulation set-up parameter

\begin{tabular}{|c|c|c|}
\hline No & Parameter & Selected Value \\
\hline $\mathbf{1}$ & CFD Solver & Pressure-Based \\
\hline $\mathbf{2}$ & Viscous Model & Realizable, k- $\varepsilon$ Model \\
\hline $\mathbf{3}$ & Species Model & Partially Premixed Combustion \\
\hline $\mathbf{4}$ & Boundary Conditions & UDF \\
\hline $\mathbf{5}$ & Solutions Methods & Second Order Upwind \\
\hline $\mathbf{6}$ & Solutions Controls & Retained as default \\
\hline $\mathbf{7}$ & Residual & $1 \times 10^{-5}$ \\
\hline
\end{tabular}

\section{RESULTS AND DISCUSSION}

This section presents and discusses the results which were obtained from the numerical approach. At the beginning of the this section, Cold simulations of the air and fuel were run at different conditions in order to investigate the effect of mixing length and the fuel velocity on the premixing level between the fuel and air. This will help to develop a better understating of the generated flames as the flame characteristics depends mainly on condition of the jet flow at the exit of the mixing chamber. For sake of verification, the calculated equivalence ratios will be then compared to the Computational equivalence ratios at different mass flow rates of fuel.

Stability study will then be made to investigate the effect of the mixing length and conical nozzle geometry on the stability of the flame. This was made to determine the optimal configuration of the burner beyond which the flame is said to be less stable. Once the optimum configuration is determined, two sets of flames were then selected at the optimum configuration to conduct further analysis of the flame mean structure.

\section{Cold Simulation (Non-Reactive)}

Effect of the Mixing Length on the Degree of Partially Premixing:

The mixing length (L/D) has a direct influence on the gradient of concentration in the mixture at the jet exit and because of this; the mixing length has a control over the local level of partially premixing as well as scalar dissipation in the combustion chamber [28]. The process of the air/fuel mixing inside the concentric tubes and the level of partially premixing at various mixing length (L/D) could be more understood from numerical results presented by [28]. At the region near the fuel inlet, it can be observed the development of an axisymmetric vortex ring. Such phenomenon occurs due to the difference in velocity across the interface between two flows, which is also known as the Kelvin-Helmholtz instability [29].

The generated Kelvin-Helmholtz vortices results in a big scale roll-up of air pockets and fuel which leads to more efficient mixing of the air and fuel. The numerical results presented in Figure 7 shows a good agreement with LES results [28]. 


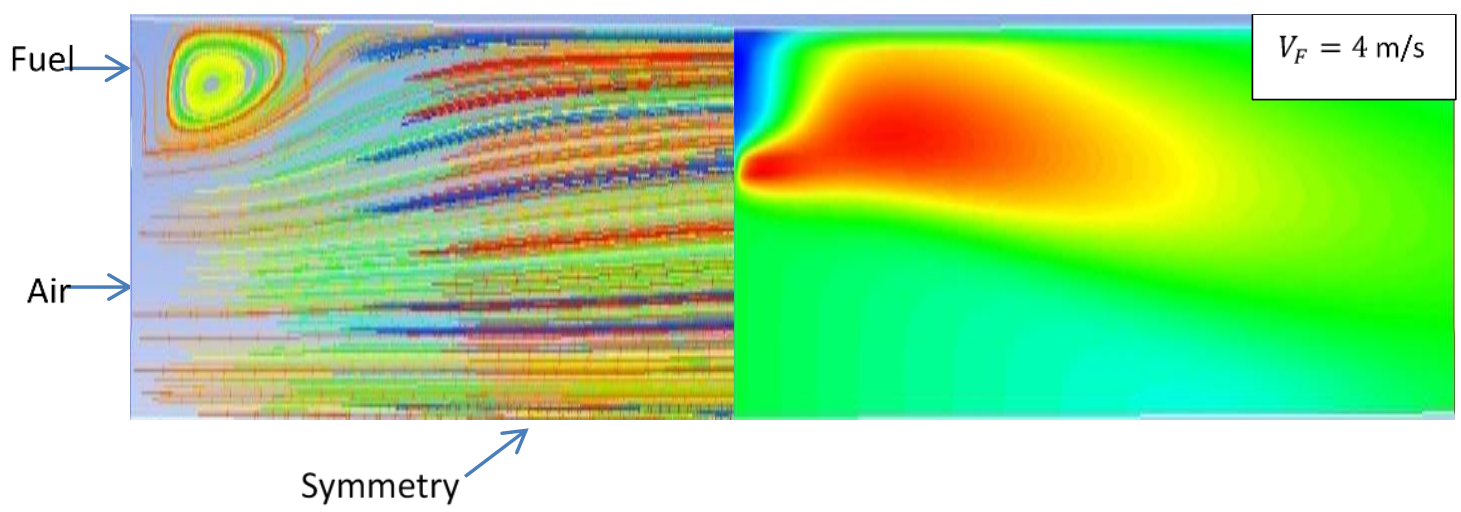

Figure 7. Path lines and turbulence intensity

For further analysis of the mixing length effect on the concentration gradient in the fuel air mixture, a 3D Model of the mixing chamber was used to run a cold simulation. Once the simulation was converged, several planes of $\mathrm{O} 2$ and $\mathrm{CH} 4$ were taken for different mixing lengths. It was found that as the mixing length (L/D) increases, the degree of the partially premixing increases proportionally. At smaller values of $\mathrm{L} / \mathrm{D}$, there is almost no premixing which in turns lead to generating diffusion flame. As the mixing length increases, more fuel air mixture is predicted till it gets to fully premixed. This can be seen in Figure 8.

Effect of the Fuel Velocity on the Degree of Partially Premixing:

Beside the mixing length effect, the fuel velocity has also a significant effect on the gradient concentration in the mixture. Thus, three different velocities where simulated while keeping the other parameters constant. From the numerical result, shown in Figure 9, it can be seen that increasing the fuel velocity leads to an increase in the level of the partially premixing

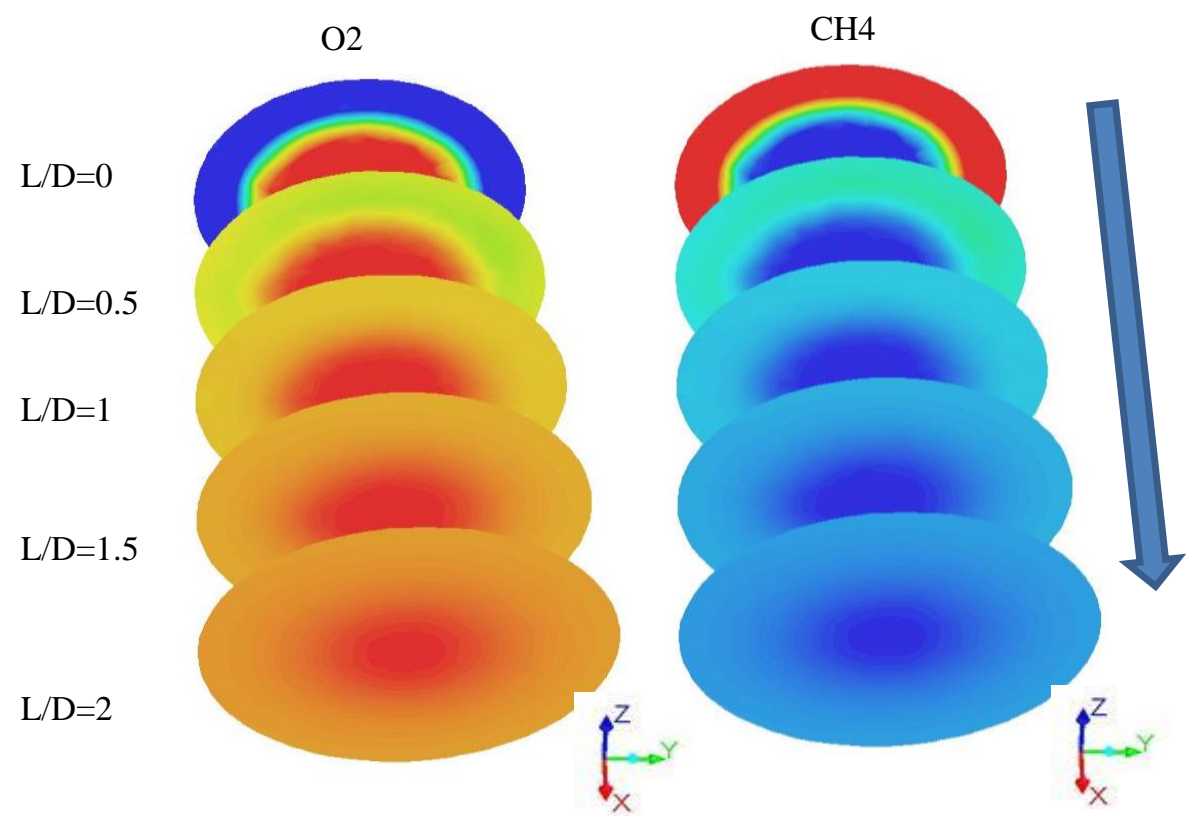

Figure 8. $\mathrm{O} 2$ and $\mathrm{Ch} 4$ concentrations for different mixing lengths 


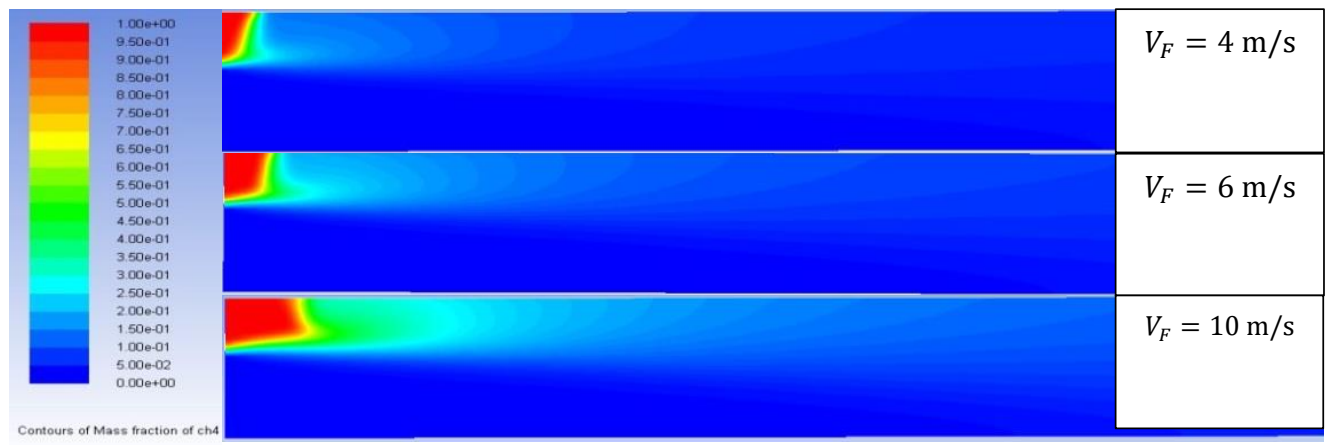

Figure 9. Contours of the mass Fraction of $\mathrm{CH} 4$ for varied velocities.

To further analyse of the effect of fuel velocity, radial profile of the mass fraction of $\mathrm{CH} 4$ was plotted at $\mathrm{L} / \mathrm{r}=6$ for three different fuel velocities. It can be clearly seen that the level of the mixing is higher at higher fuel velocity, as shown in Figure 10.

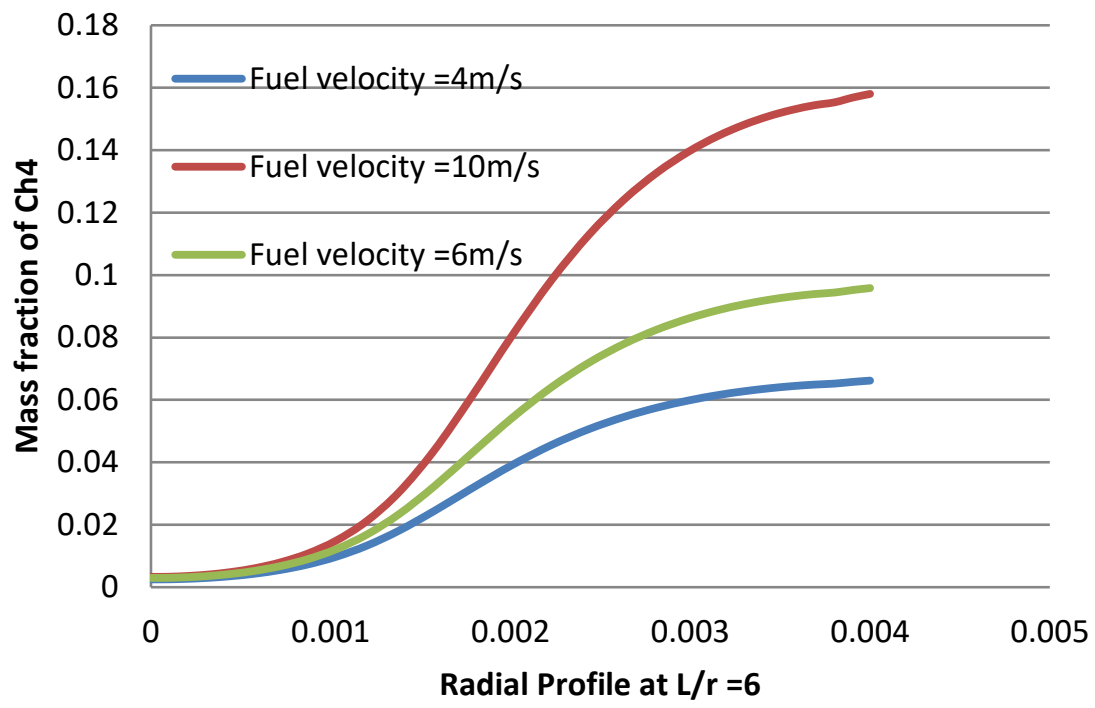

Figure 10. Radial profile of the mass fraction of $\mathrm{CH} 4$ for varies velocities

Verification of the Computational Results

The computational results of the jet equivalence ratios were compared with the calculated values in cold flow for the sake of verification. It can be seen from Figure 11 that the computational results are with a good agreement with the calculated results (See Appendix B). In addition, the simulation shows a good prediction of the equivalence ratio at low fuel flow rate, however as the fuel flow rate increases the gap between the computational and the calculated values increases slightly. This could be due to a slight lack in the quality of the mesh or numerical error during the calculations. 


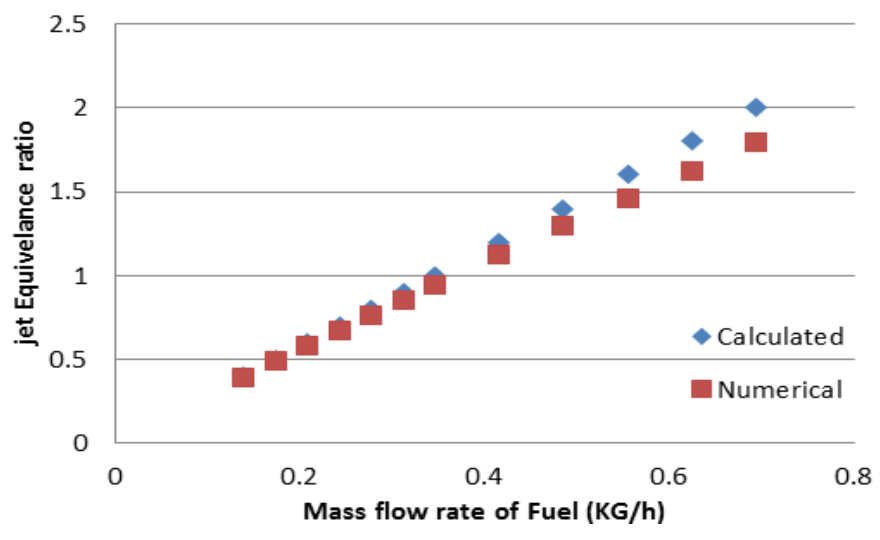

Figure 11. Comparison between computational and calculated results for different fuel flow rates

\section{Reactive Simulations}

Stability Limit of the Conical Nozzle Burner:

The stability characteristics of the present burner were studied based on the two following parameters:

- The level of partial premixing.

- Cone angle of the nozzle.

The level of premixing was conducted by modifying the mixing length, L. In this study the mixing length was altered from $0 \mathrm{~cm}$ to $9 \mathrm{~cm}$. The stability limit of the burner is defined in this study as the point above which the flame is considered to be sustained and stable. The stability point was obtained by reducing the rate of the fuel flow while keeping the air flow rate constant. This point was recorded at the lowest flow rate (lowest equivalence ratio $\Phi$ ) which corresponds to unsustainable or extinguished flame. Both attached flames and lifted flame were observed and presented in this study. This run was carried out at $6 \mathrm{~kg} / \mathrm{hr}$ of air flow rate and the data shown in Figure 13 was obtained using pure methane $(100 \% \mathrm{CH} 4)$. Figure 12 represents the data as jet equivalence ratio vs the L/D ratio, where $\mathrm{L}$ is the mixing the length (variable) and $\mathrm{D}$ is the nozzle diameter (Fixed value and equal to $8 \mathrm{~mm}$ ), for different cone angles.

Generally, it was observed from Figure 12 that there is a specific point at all curves which offers better stability limit with lowest Equivalence ratio. This point was noticed to occur at the L/D of 5 for all cone angles and beyond which the flames were observed to be less stable. It was also found that the stability of the flames at lower value of the $(\mathrm{L} / \mathrm{D}<5)$ towards diffusion conditions are lower than that for the $(\mathrm{L} / \mathrm{D}>5)$ where more mixing of the fuel and air is predicted due the higher mixing length.

Mixing the air and the fuel prior to the combustion chamber, leads to combustion of non-homogenous mixture which is likely to generate a structure of multi reaction zones, namely, diffusion, lean and rich [18]. Such structure occurs as a result of interaction of the rich pockets with the lean pockets in the flame. The reaction zones resulting from this interaction is likely to create triple flame structure which is able to survive at high turbulence intensities. Several studies had observed the triple flame structure in the partially premixed flames $[1,19,20]$.

Thus in the present study, there is a high possibility of forming triple flame structure at $\mathrm{L} / \mathrm{D}=5$ and this, could be the main reason behind the high stability level at this specific level of premixing. As it can be seen from Figure 12 that the stability curve at the non-premixed conditions is steeper which proves that partially premixed flames can survive better than the non-premixed and premixed flames. Furthermore, the non-premixed has the worst stability characteristics, as shown in Figure 12. 


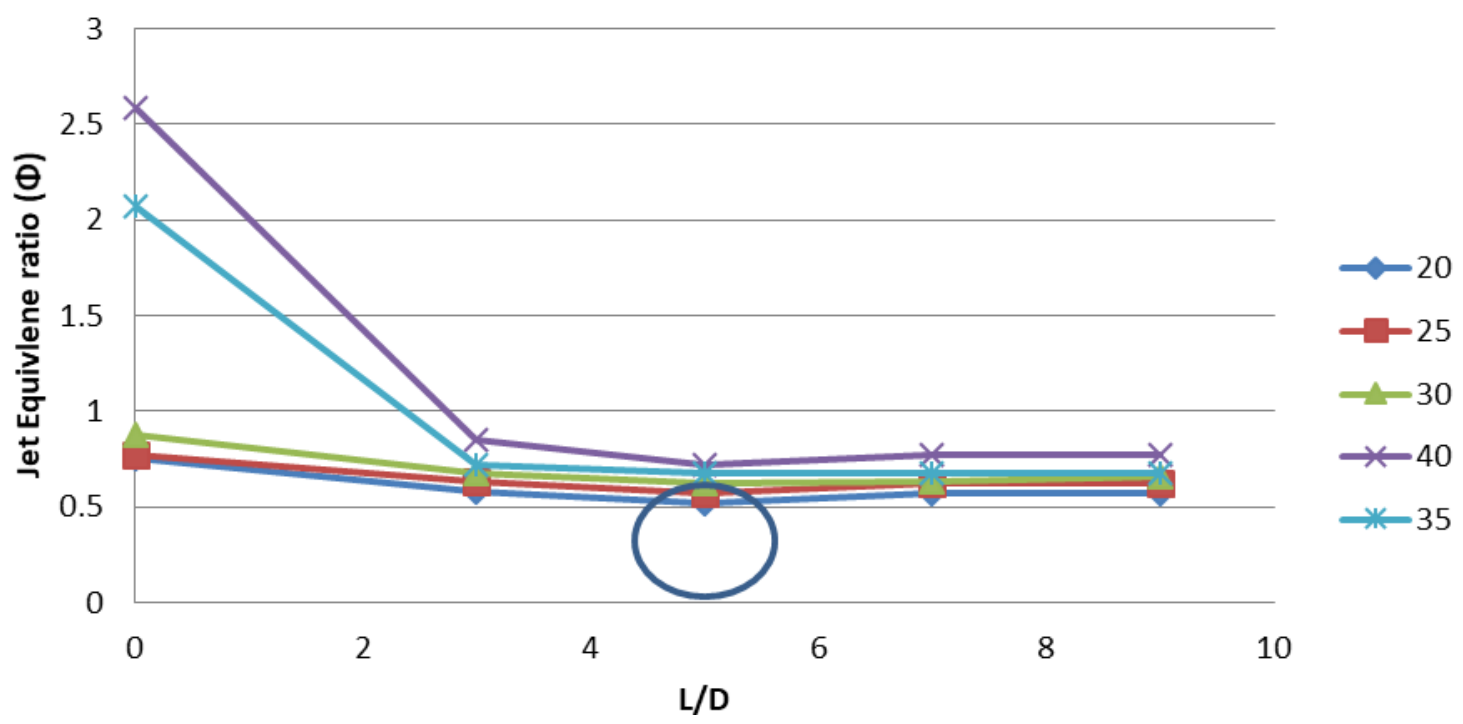

Figure 12. "Stability Curve " Equivalence ration vs the L/D

\section{Mean Flame Structure}

Two sets of flames were selected at different conditions to conduct further analysis and develop a better understanding of the flame behaviours at different cone angles, while keeping $\mathrm{L} / \mathrm{D}=5$.

\section{First Flames Set}

Table 4. First set of flames

\begin{tabular}{|c|c|c|c|}
\hline Flame & $\begin{array}{c}\mathbf{U}_{\mathbf{J}} \\
(\mathrm{m} / \mathrm{sec})\end{array}$ & $\mathbf{\Phi j}$ & $\mathbf{R D}$ \\
\hline PP20I & 32 & 0.519 & 0.5 \\
\hline PP25I & 30.5 & 0.57 & 0.5 \\
\hline PP30I & 27.8 & 0.622 & 0.5 \\
\hline
\end{tabular}

Three different partially premixed flames, as shown above in table 4, were selected to study the flame characteristics at the same level of stability $(L / D=5)$. These flames were selected at different cone angles with Relative Deviation kept constant. The relative deviation (RD) can be calculated using the following equation.

$$
\mathrm{RD}=\frac{\Phi_{\mathrm{j}}-\Phi_{\mathrm{E}}}{\Phi_{\mathrm{E}}}
$$

Where the $\Phi_{j}$ represent the jet equivalence ratio and $\Phi_{E}$ stands for the equivalence ratio at extinction limit at $\mathrm{L} / \mathrm{D}=5.50 \%$ was selected as $\mathrm{RD}$ for the selected flames. 
Journal of Thermal Engineering, Research Article, Vol. 5, No. 5, pp. 422-445, October, 2019

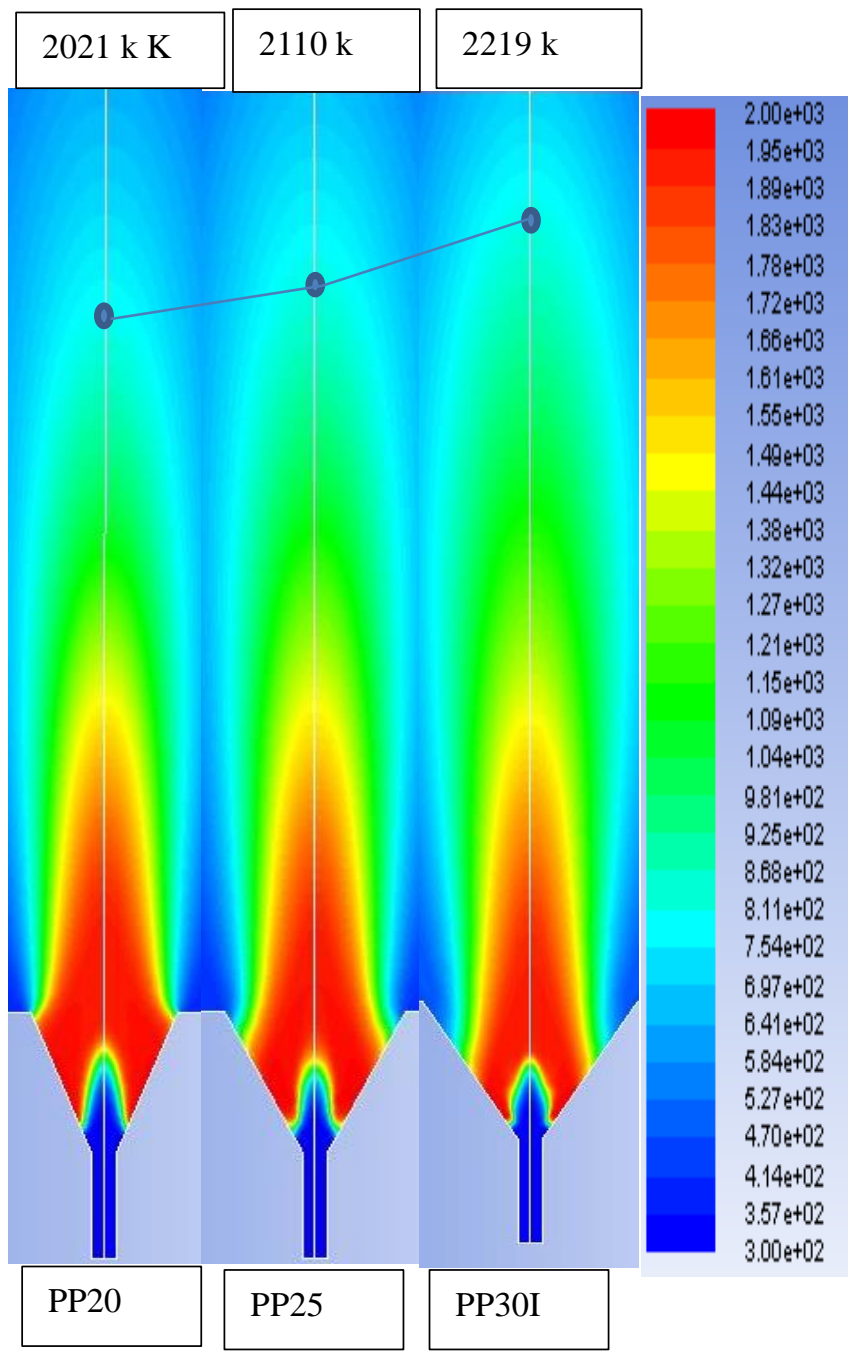

Figure 13. Contours of temperature for PP20I, PP25I and PP30I

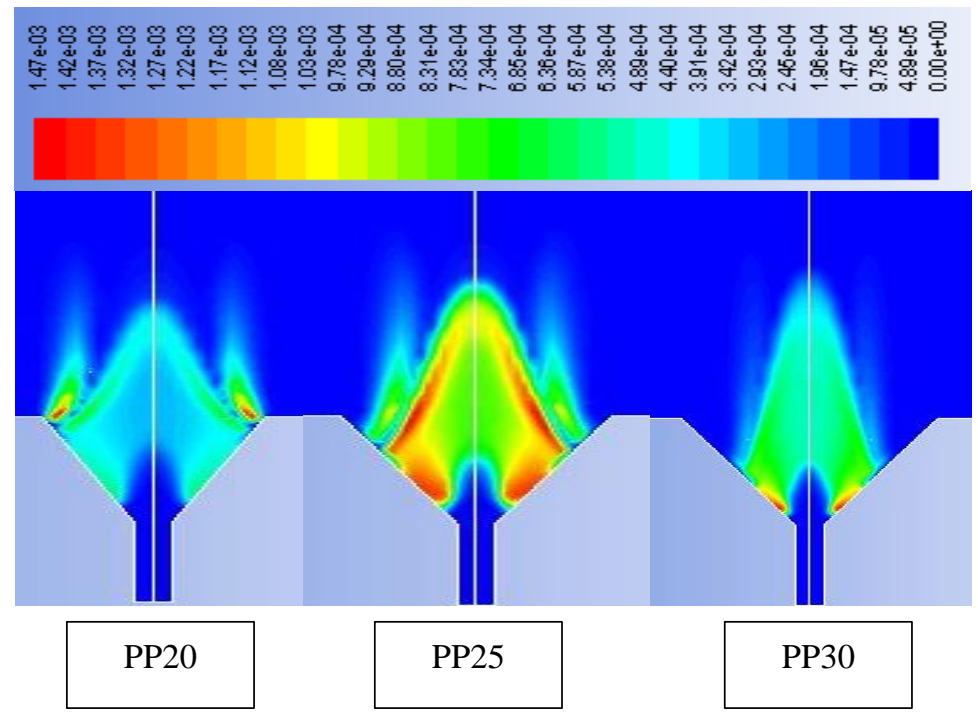

Figure 14. Contours of the mass fraction of $\mathrm{CO}$ 


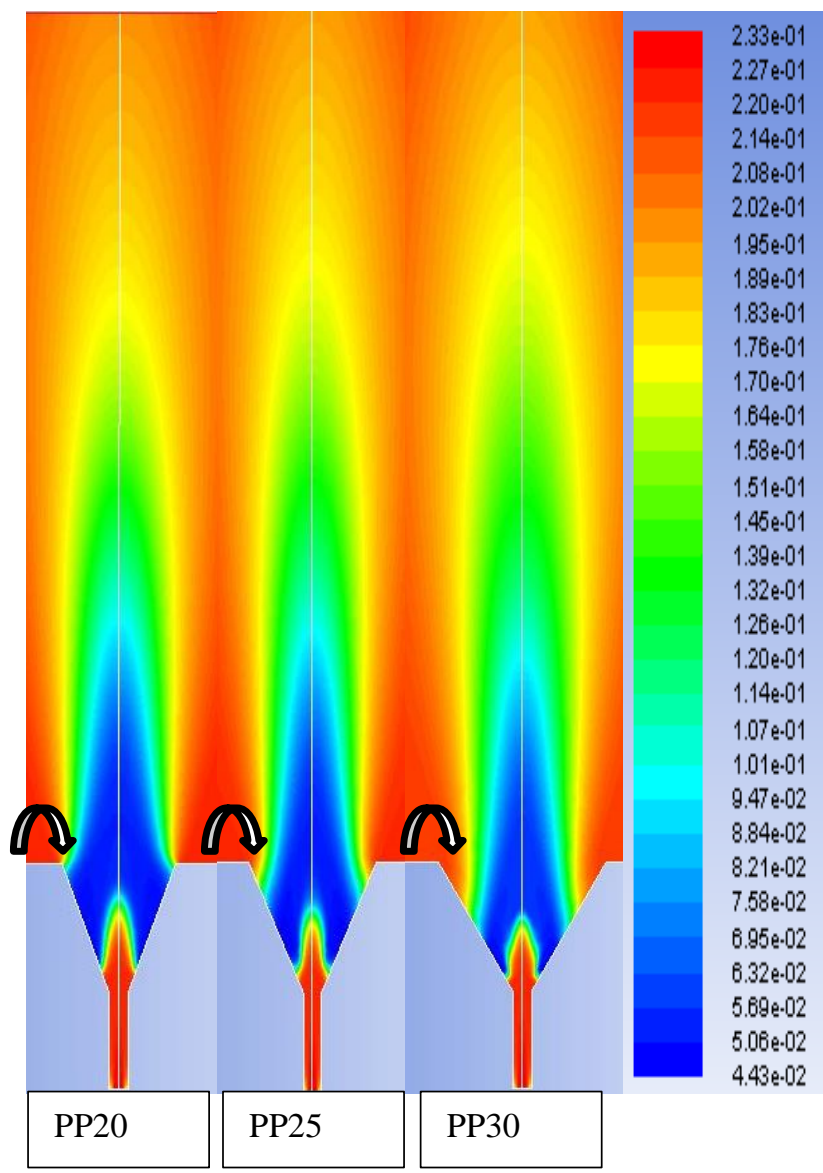

Figure 15. Contours of mass fraction of the O2 for PP20I, PP25I and PP30I

$\mathrm{OH}$ and Rayleigh measurements taken by [1] for the same burner at 26 cone angle found that the partially premixed flames are mainly stable by the presence of the intense reaction core within the conical nozzle which is also known as the stabilization core. The present numerical data support the $\mathrm{OH}$ measurements reported by [1] and thus it can be concluded that the intene reaction or stabilisation core is the main responsible factor for highly stabilization characteristics of the partially premixed flames. It was also noticed from the numerical data that the cone angle has a direct effect on the stabilization core. Increasing the cone angle was found to make the stabilization core narrower as shown in Figure 14.

Moreover, increasing the cone angle was found to increase the air entrainment inside the conical nozzle. The air entrainment is believed to cause a necking of the stabilization core and with a higher cone angle the stabilization core is expected to break. This can cause the flame to blow off as a result of the expected extinction of the intense reaction core. The effect of air entrainment can be clearly seen from the contours of $\mathrm{O} 2$ mass fraction, where the increase of the cone angle causes more air to enter inside the conical nozzle. However, the numerical result shows that almost no air entrainment is observed at cone angle of 20 which indicates that the there is no effect caused by the surrounding on the stabilization core at early stage. These findings are supported by reported experimental data [17] where a smoke tracer was used to detect air entrainment for cone angle of 20, however, no smoke tracer was detected which agrees with the numerical results of this study.

Moreover, increasing the cone angle was found to increase the air entrainment inside the conical nozzle. The air entrainment is believed to cause a necking of the stabilization core and with a higher cone angle the stabilization core is expected to break. This can cause the flame to blow off as a result of the expected extinction of the intense reaction core. The effect of air entrainment can be clearly seen from the contours of $\mathrm{O} 2$ mass fraction, where the 
increase of the cone angle causes more air to enter inside the conical nozzle (Figure 15). However, the numerical result shows that almost no air entrainment is observed at cone angle of 20 which indicates that the there is no effect caused by the surrounding on the stabilization core at early stage. These findings are supported by reported experimental data [17] where a smoke tracer was used to detect air entrainment for cone angle of 20, however, no smoke tracer was detected which agrees with the numerical results of this study (Figure 16).

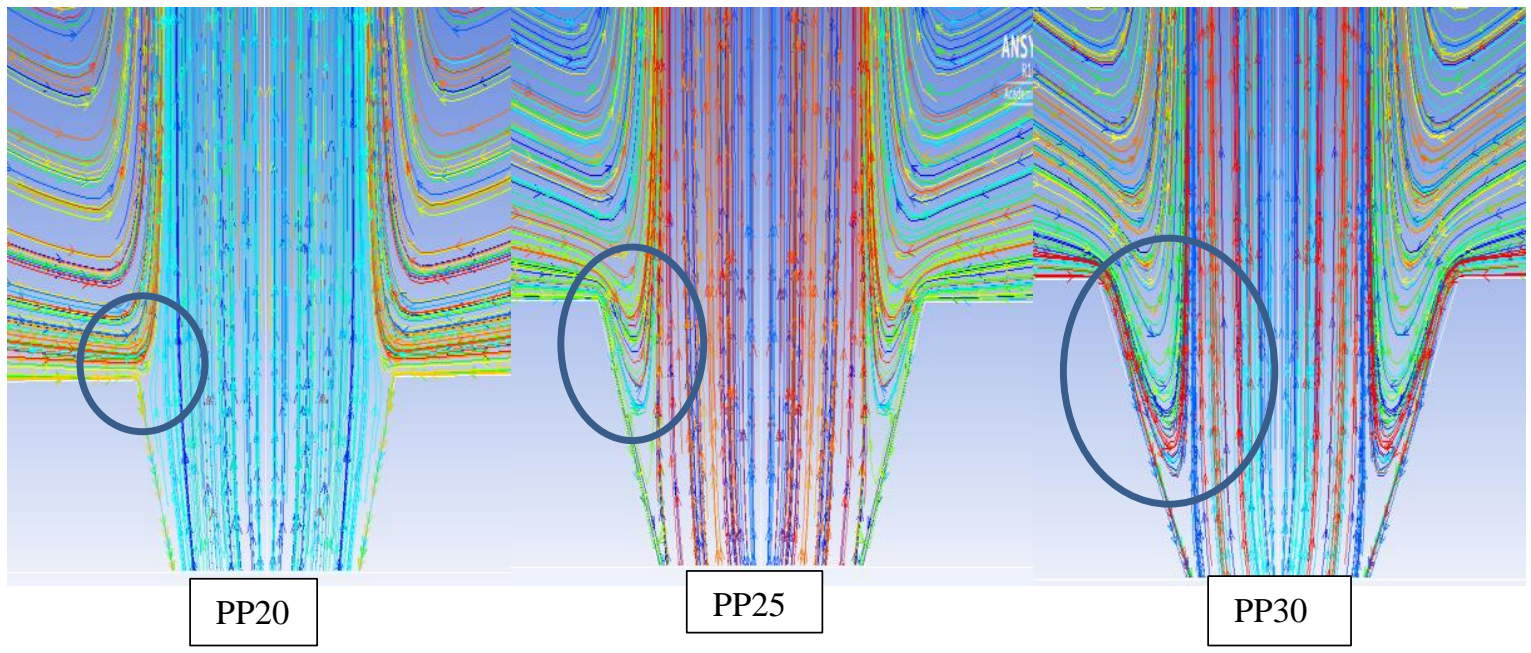

Figure 16. Path lines for different cone angles

Figure 17, shows the numerical results, for three different flames with same stability, mixing length equal to 5, for 20, 25 and 30 degrees cone angles. Experimental observations for similar flames, reported [17] that as the cone angle increased, the flame attachment to the wall decreased and the same findings can be seen from the numerical results illustrated in Figure 17 of this study.

\section{Second Flames Set}

The flames shown in the table 5 are selected to study the effect of changing the cone angle on the flame structure while the air and fuel flow rates are kept constant.

Table 5. Second Set of the Flames.

\begin{tabular}{|c|c|c|c|}
\hline Flame & $\begin{array}{c}\text { UJ } \\
(\mathrm{m} / \mathrm{sec})\end{array}$ & $\mathbf{\Phi j}$ & $\mathbf{R D}$ \\
\hline PP20II & 32 & 0.933 & 0.797 \\
\hline PP25II & 32 & 0.933 & 0.636 \\
\hline PP30II & 32 & 0.933 & 0.5 \\
\hline
\end{tabular}

This set of flames will cover the axial profile (along the central line) and the radial profile across the rim of the nozzle for the selected flames. These profiles will be taken for the temperature and species concentration (O2 and $\mathrm{CO})$. As stated earlier, these flames are mainly selected to investigate the influence of the cone angle at fixed jet equivalence ratio of 0.933 and jet velocity of $32 \mathrm{~m} / \mathrm{s}$ with varied Relative Deviation. 


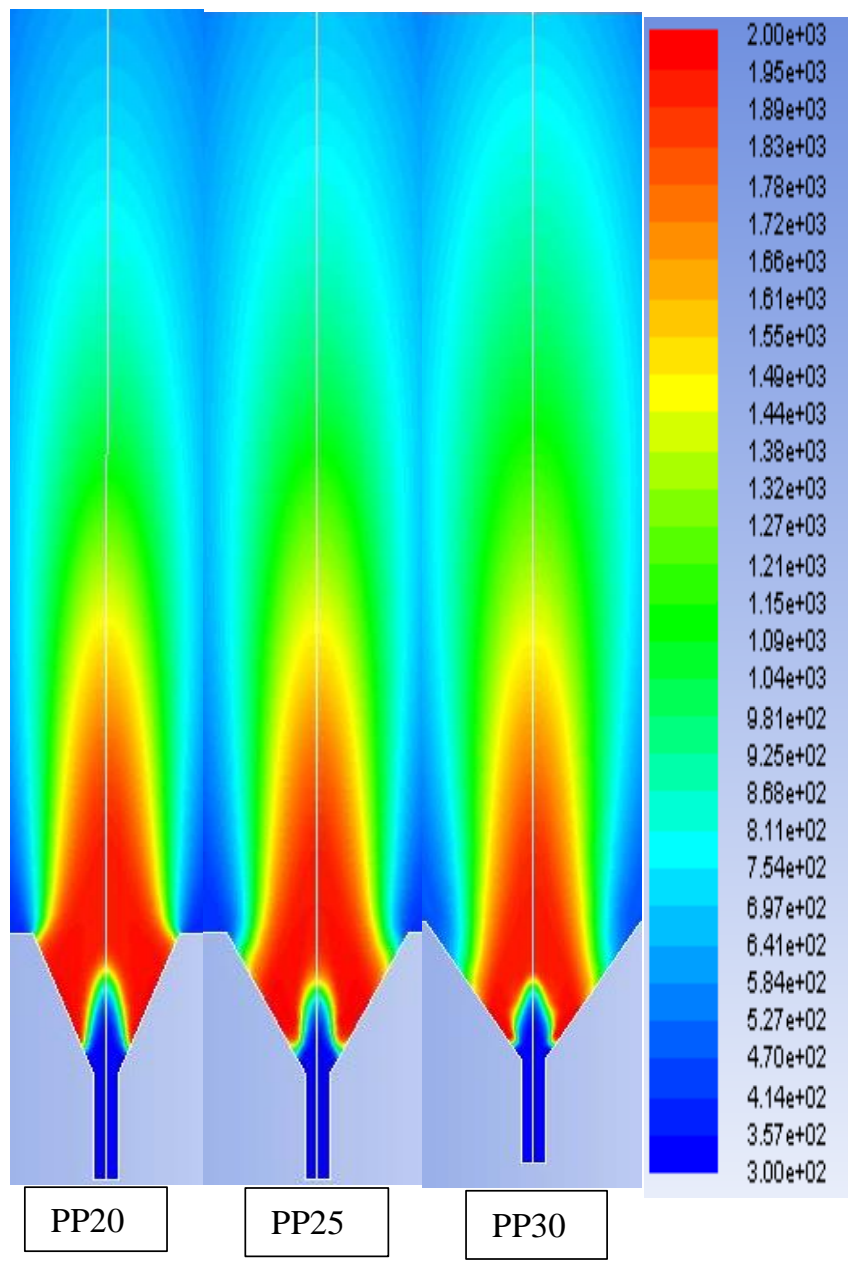

Figure 17. Numerical data demonstrated, increase in the cone angle from $20^{\circ}$ (left) to $30^{\circ}$ (right) decreased the flame wall attachment

Figure 18 illustrates the axial and radial profile for the selected flames covering the temperature and the concentration of the $\mathrm{O} 2$ and $\mathrm{CO}$. The data plotted in Figure 19 shows that increasing the value of the cone angle causes the stabilization core to be longer and narrower, where the temperature and the concentration of the $\mathrm{CO}$ are high and the concentration of $\mathrm{O} 2$ is low. This effect can be explained, as discussed earlier, as a result of the air entrainment into the nozzle that causes the flame to squeeze and therefore elongate it. This result shows a good agreement with the data available in the public domain [17].

Flow Field

Figure 19a shows the velocity vectors of flow inside the cone indicating the existence of a recirculation zone near the wall of the conical nozzle which is believed to improve the overall stability performance of the burner. These recirculation zones were found to form for the cone angle lower than 30 degree and beyond which the recirculation zone is broken due to the excessive air entrainment, as shown in Figure 19b. 


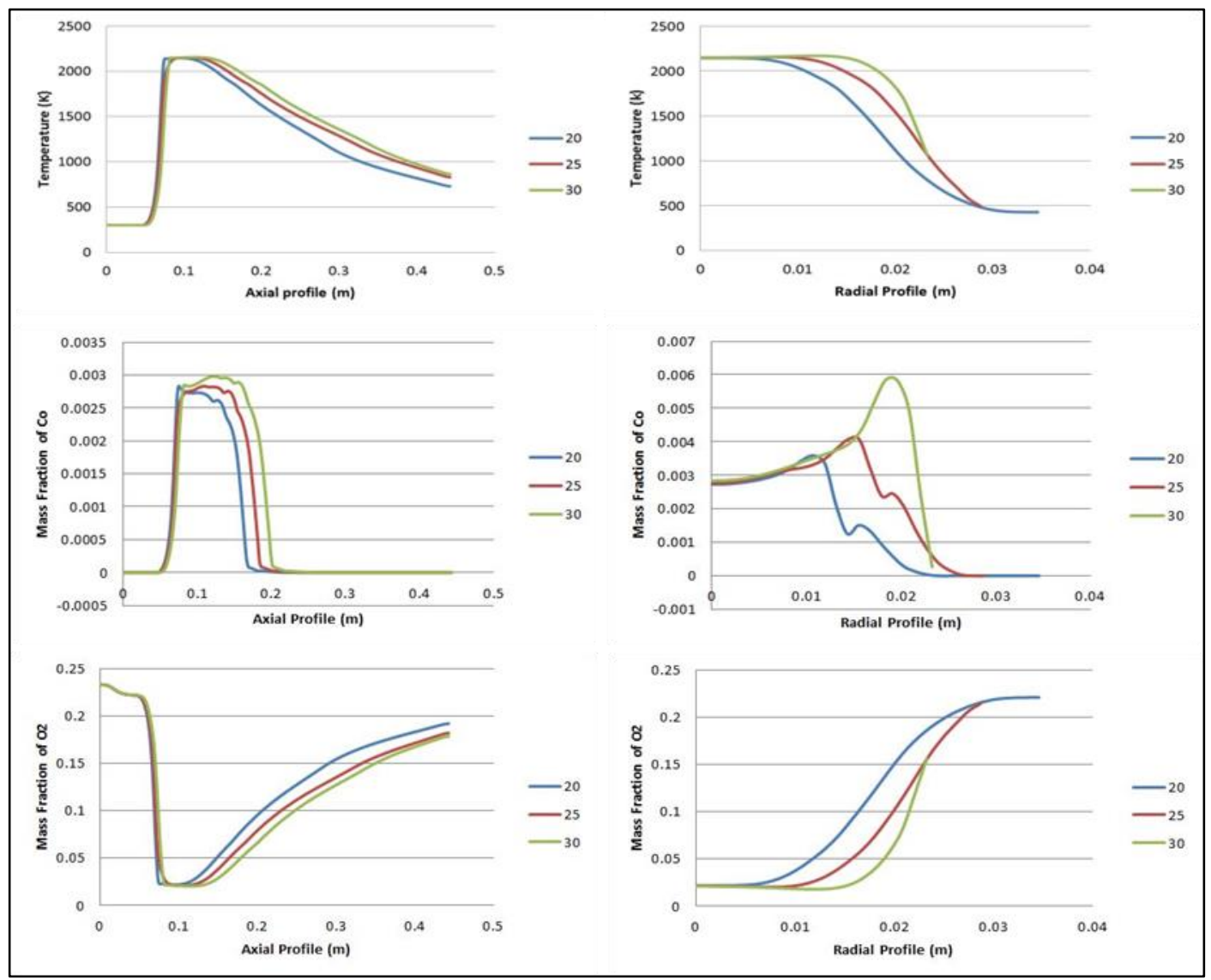

Figure 18. Temperature, $\mathrm{CO}$ and $\mathrm{O} 2$ concentration for the axial and radial profiles

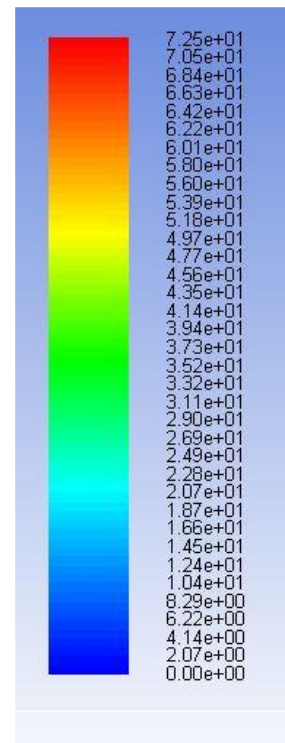

Pathlines Colored by Velocity

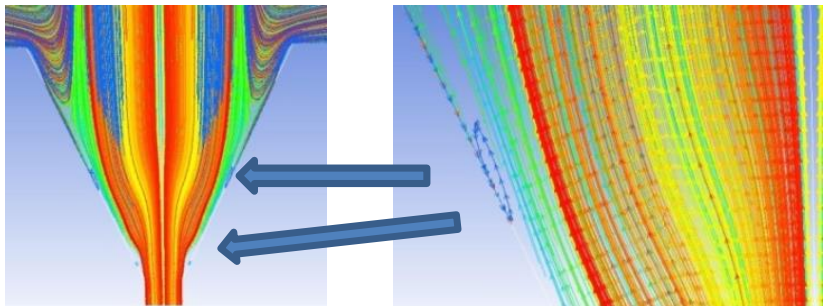

(a)

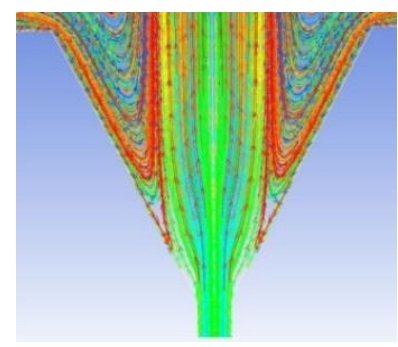

(b)

Figure 19. (a) Path lines of the velocity for the recirculation zone of 25 degrees, (b) Path line inside the burner for 35 degrees

The numerical findings of this study [30] compared favourably with the experimental study [13] which showed a development of recirculation zone at early stage of the flame inside the conical nozzle. 
Journal of Thermal Engineering, Research Article, Vol. 5, No. 5, pp. 422-445, October, 2019

\section{CONCLUSION}

The present study used a numerical approach to conduct a thorough investigation of the effect of the mixing length and the cone angle on the stability of a conical burner flame. FLUENT 16.1 was utilised in this investigation in order to carry out the necessary calculations for the governing equations of the flow with turbulent model of K- $\varepsilon$ and the Partially Premixed Combustion model. The numerical data was found to be in good agreement with measurement experimental data $[3,17,19]$. This present study led to the following conclusions:

i. Development of an axisymmetric vortex ring was noticed at the region near the fuel inlet. Such phenomena occur due to the difference in velocity across the interface between two flows, which is also known as the Kelvin-Helmholtz instability. The generated Kelvin-Helmholtz vortices results in a big scale roll-up of air pockets and fuel which leads to more efficient mixing of the air and fuel.

ii. It was found that as the mixing length (L/D) increased, the degree of the partially premixing increased proportionally. At smaller values of $\mathrm{L} / \mathrm{D}$, there is almost no premixing which lead to generating diffusion flame. As the mixing length increased, more fuel air mixture is predicted creating fully premixed flames. Therefore, it can be concluded that the L/D plays a significant role when it comes to determining the characteristics of the flame.

iii. It was also found that the fuel velocity has also a significant effect on the gradient concentration in the mixture. Increasing the fuel velocity resulted in higher gradient concentration in the mixture.

iv. The numerical results showed that there is a specific point at all curves which offered better stability limit with lowest Equivalence ratio. This point was noticed to occur at the L/D of 5 for all cone angles and beyond which flames were observed to be less stable. Thus, $\mathrm{L} / \mathrm{D}=5$ is the optimal configuration that generates the most stable flame. This finding means that the burner can operate at very lean mixture which enables the burner to achieve low flame temperature and this leads to low level of NOx pollutants.

v. The numerical findings also show that all selected flames exhibited a strong presence of intense reaction core starting at early stage of the flame inside the conical nozzle with high temperature, low concentration of $\mathrm{O} 2$ and high concentration of $\mathrm{CO}$. The intense reaction or stabilisation core is believed to be the main responsible factor for highly stabilization characteristics of the partially premixed flames.

vi. Increasing the cone angle was found to increase the air entrainment inside the conical nozzle. The air entrainment is believed to cause a necking of the stabilization core and with a higher cone angle the stabilization core is expected to break. This can cause the flame to blow off as a result of the expected extinction of the intense reaction core.

vii. Increasing the value of the cone angle causes the stabilization core to be longer and narrower, where the temperature and the concentration of the $\mathrm{CO}$ are high and the concentration of $\mathrm{O} 2$ is low. This occurs as a result of the air entrainment into the nozzle that causes the flame to squeeze and therefore elongate it.

\section{NOMENCLATURE}

$\mathrm{L}$

$\mathrm{D}$

$\mathrm{U}_{\mathrm{j}}$

RD

$\Phi_{\mathrm{j}}$

$\Phi_{\mathrm{E}}$

$N$

DA

PP20I

PP25I

PP30I

PP20II

PP25II

PP30II

Greek symbols
Mixing length, mm

Diameter, $\mathrm{mm}$

Jet velocity, $\mathrm{m} / \mathrm{s}^{2}$

Relative deviation, nd

Jet equivalence ratio, nd.

Extinction jet equivalence ratio, nd.

Degree of freedom, nd

Damkolhar number, nd.

Partially premixed, Cone angle $20^{\circ}$, First flame set, nd

Partially premixed, Cone angle $25^{\circ}$, First flame set, nd

Partially premixed, Cone angle $30^{\circ}$, First flame set, nd

Partially premixed, Cone angle $20^{\circ}$, Second flame set, nd

Partially premixed, Cone angle $25^{\circ}$, Second flame set, nd

Partially premixed, Cone angle $30^{\circ}$, Second flame set, nd 


$\begin{array}{ll}\Phi & \text { Equivalence ratio } \\ \text { Subscripts } & \text { Refers to jet } \\ J & \text { Refers to Extinction }\end{array}$

\section{APPINDEX A}

\section{User-Defined Function (UDF)}

User-Defined Function (UDF) is defined as a function which can be programmed by the users. This programmed function is then loaded into the FLUENT in order to improve the standard features of the code. This tool can be used to define users' own boundary conditions. This function can be written in $\mathrm{C}$ programming language by utilising any TYPE of text editor.

By default, Fluent sets the inlet velocity to enter with uniform velocity across the inlet boundary. This mean that the velocity at the mid of the tube will be the same as the velocity near the edge of the tube. However, this is not what actually happens in the tube. In real world, the velocity is at highest in the mid of the tube and it decreases gradually towards the wall $\mathrm{t}($ velocity $=0$ ). This occurs due to no slip condition. Thus, the Fluent Default setting for the inlet boundary conditions will lead to a poor simulation of the flow through the tube. Thus, in order to enhance the standard features of the code for the boundary conditions, this study has used a C code for the parabolic Velocity inlet for the air and fuel inlet. The $\mathrm{C}$ code was then loaded into the Fluent as UDF. This UDF was then selected in the velocity boundary window in FLUENT.

The difference between the Defaults setting and the UDF for the velocity profile across the inlet can be seen in Figure A1.

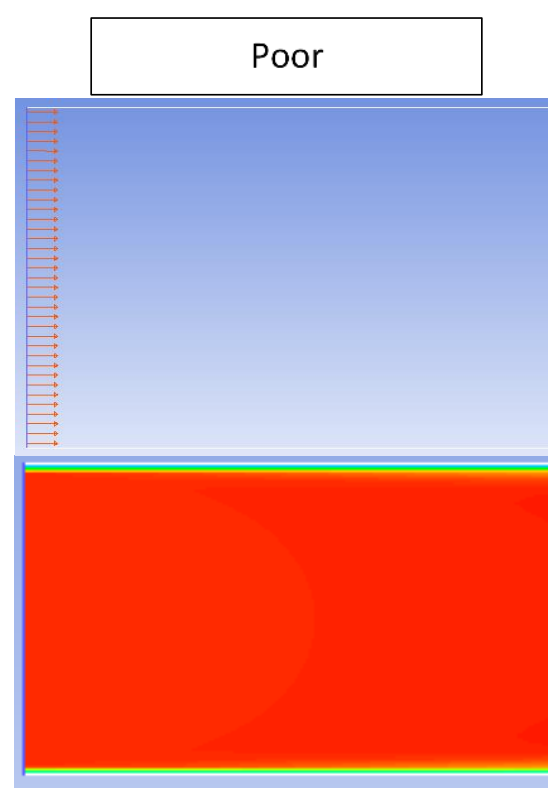

Default

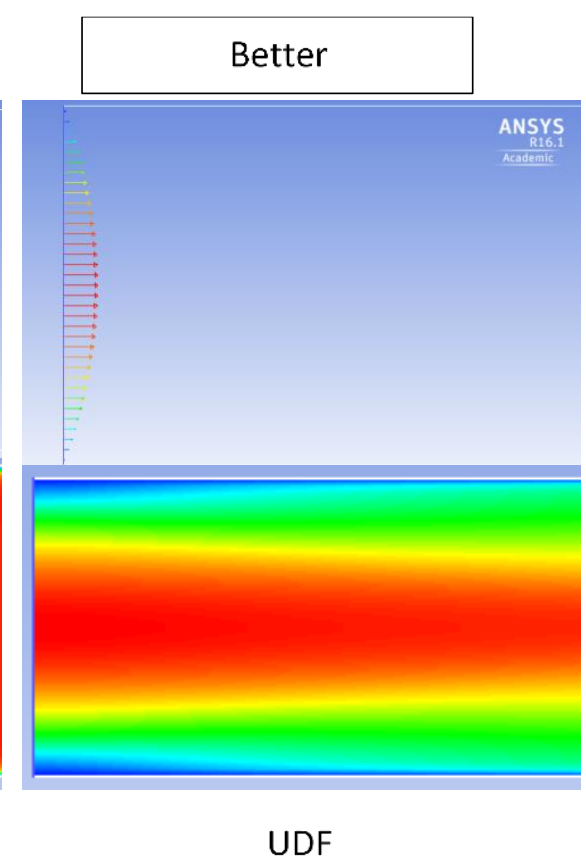

UDF

Figure A1. Difference between Default setting and UDF for velocity profile across the inlet.

\section{APPINDEX B}

This section covers several calculations that will be used for the boundary conditions at the set-up stage and will contribute in the selection process for the right viscous model for the tested flows. These calculations include:

1. Calculating the Mass flow rate for air and fuel inlet for different Equivalence ratios $(\Phi)$. 
2. Calculating the air and fuel inlet velocities using the mass flow rate.

\section{Mass Flow rate Calculation}

This section covers several calculations that will be used for the boundary conditions at the set-up stage and will contribute in the selection process for the right viscous model for the tested flows. These calculations include:

1. Calculating the Mass flow rate for air and fuel inlet for different Equivalence ratios $(\Phi)$.

2. Calculating the air and fuel inlet velocities using the mass flow rate.

Mass Flow rate Calculation:

Methane-air reaction occurs when the methane reacts with the oxygen and results in carbon dioxide and water plus the released heat [23]. The following expression represents the chemical reaction for the Methane-air:

$$
\mathrm{CH}_{4}+2\left(\mathrm{O}_{2}+3.76 \mathrm{~N}_{2}\right)=\mathrm{CO}_{2}+2 \mathrm{H}_{2} \mathrm{O}+7.52 \mathrm{~N}_{2}
$$

This reaction is said to be stoichiometric when the fuel is completely burned. The stoichiometric fuel to air ratio of the methane air reaction can be calculated as following:

$$
\begin{gathered}
\frac{\text { Fuel }}{\text { Air }}=\frac{C H_{4}}{2\left(O_{2}+3.76 N_{2}\right)} \\
\frac{\text { Fuel }}{\text { Air }}=\frac{(12+4)}{2(2 * 16+3.76 * 28)}=0.058 \\
\frac{\text { Air }}{\text { Fuel }}=\frac{1}{0.058}=17.16
\end{gathered}
$$

The equivalence ratio of the combustion can be calculated using the following equation:

$$
\begin{gathered}
\text { Equivalence ratio }=(\text { Fuel }- \text { to }- \text { oxidiser ratio }) /(\text { Fuel }- \text { to }- \text { oxidiser ratio })_{\text {stoc }} \\
\qquad \begin{array}{c}
\emptyset \frac{\left(\frac{m_{f}}{m_{a}}\right)_{\text {act }}}{\left(\frac{m_{f}}{m_{a}}\right)_{\text {sto }}} \\
\left(\frac{m_{f}}{m_{a}}\right)_{\text {sto }}=0.058 \\
\left(\frac{m_{f}}{m_{a}}\right)_{\text {act }}=0.058 \times \emptyset \\
\mathrm{m}_{\mathrm{f}}=0.058 \times \emptyset \times \mathrm{m}_{\mathrm{a}}
\end{array}
\end{gathered}
$$


Equation (B.1) will be used to calculate the required mass flow rate of fuel to achieve different equivalence ratios at constant air mass flow rate of $5.98 \mathrm{Kg} / \mathrm{h}$. For example, the required mass fuel rate for equivalence ratio $(\emptyset=$ 2) can be calculated as following:

$$
m_{f}=0.058 \times 1 \times 5.98 \frac{\mathrm{Kg}}{\mathrm{h}}=0.3468 \frac{\mathrm{kg}}{\mathrm{h}}=9.633 * 10^{-5} \mathrm{~kg} / \mathrm{s}
$$

\section{Calculation the fuel and air inlet velocity}

The air and fuel inlet velocities can be calculated using the mass flow rate equations, as shown below:

$$
m_{a}=p * A * V
$$

where,

$\mathrm{p}=$ density $\left(\mathrm{kg} / \mathrm{m}^{3}\right) \quad$ where Air density $=1.18 \mathrm{~kg} / \mathrm{m}^{3}$ and methane density $=0.66 \mathrm{~kg} / \mathrm{m}^{3}[23]$.

$\mathrm{A}=\operatorname{Area}\left(\mathrm{m}^{2}\right)$.

$\boldsymbol{m}_{\boldsymbol{a}}=$ flow rate of air $=9.63 * 10^{-3} \mathrm{~kg} / \mathrm{s}$ for equivalence ratio of one.

$\boldsymbol{m}_{\boldsymbol{f}}=$ flow rate of fuel $=0.001661 \mathrm{~kg} / \mathrm{s}$ for equivalence ratio of one .

Area of air inlet $=1.96 * 10^{-5} \mathrm{~m}^{2}$

Area of fuel inlet $=2.2 * 10^{-5}$

This equation was used to calculate the fuel and air inlet velocity for a range of equivalence ratio, as shown in the table B.1 below. These were then used during the simulation process.

Table B.1. Air and fuel inlet velocity for wide range of equivalence ratios $(\Phi)$

\begin{tabular}{|c|c|c|c|c|c|}
\hline & $\Phi$ & $\mathbf{M}_{\mathbf{a}}(\mathbf{k g} / \mathbf{s})$ & $\mathbf{V}_{\mathbf{a}}(\mathbf{m} / \mathbf{s})$ & $\mathbf{M}_{\mathbf{F}}(\mathbf{k g} / \mathbf{s})$ & $\mathbf{V F}_{\mathbf{F}}(\mathbf{k g} / \mathbf{s})$ \\
\hline 1 & 2 & 0.001661 & 71.81771 & 0.000193 & 13.2697 \\
\hline 2 & 1.8 & 0.001661 & 71.81771 & 0.000173 & 11.94273 \\
\hline 3 & 1.6 & 0.001661 & 71.81771 & 0.000154 & 10.61576 \\
\hline 4 & 1.4 & 0.001661 & 71.81771 & 0.000135 & 9.288788 \\
\hline 5 & 1.2 & 0.001661 & 71.81771 & 0.000116 & 7.961818 \\
\hline 6 & 1.0 & 0.001661 & 71.81771 & $9.63 \mathrm{E}-05$ & 6.634848 \\
\hline 7 & 0.9 & 0.001661 & 71.81771 & $8.67 \mathrm{E}-05$ & 5.971364 \\
\hline 8 & 0.8 & 0.001661 & 71.81771 & $7.71 \mathrm{E}-05$ & 5.307879 \\
\hline 9 & 0.7 & 0.001661 & 71.81771 & $6.74 \mathrm{E}-05$ & 4.644394 \\
\hline 10 & 0.6 & 0.001661 & 71.81771 & $5.78 \mathrm{E}-05$ & 3.980909 \\
\hline 11 & 0.5 & 0.001661 & 71.81771 & $4.82 \mathrm{E}-05$ & 3.317424 \\
\hline 12 & 0.4 & 0.001661 & 71.81771 & $3.85 \mathrm{E}-05$ & 2.653939 \\
\hline
\end{tabular}




\section{REFERENCES}

[1] Mansour, M. (2003). Stability characteristics of lifted turbulent partially premixed jet Flames, Combustion and Flame, 133, 236-274.

[2] INFORSE-EUROPE (2010), Regulation of air pollution from small biomass combustion, 17-19, [online] http://www.inforse.org/europe/pdfs/biomass-pollution-regulation-proposal.pdf

[3] Mansour, M. (2005). Mixing and nozzle geometry effects on flame structure and stability, Portugal, 6-10 October $2005 . \quad$ Lisbon, 23-34. http://scholar.cu.edu.eg/sites/default/files/ahmedabdelhafez/files/mixing_and_nozzle_geometry_effects_on_flame_st ructure_and_stability.pdf

[4] Miao, J. Leung, W. and Cheung, K. (2013). Flame Stability and Structure of Liquefied Petroleum Gas-Fired Inverse Diffusion Flame with Hydrogen Enrichment, International Journal of Mechanical, Aerospace, Industrial, Mechatronic and Manufacturing Engineering, 1, 121-129.

[5] Schefer, W. Wicksal, D.M. and Agrawal A.K. (2002) Combustion of hydrogen-enriched methane in a lean premixed swirl burner, Proceedings of the combustion institute, 29,1, 843-851

[6] Shoshin, Y. (2011). Stabilization of laminar inverted ultra -lean hydrogen-methane-air flames, Combustion Technology, 602-613, [online]. http://www.combustion-institute.it/proceedings/MCS-7/papers/PEC/PEC-11.pdf

[7] Alhashimi, M. (2012). Flashback and Blowoff Characteristics of Gas Turbine Swirl Combustor, 36-37. http://orca.cf.ac.uk/24193/1/2012\%20Abdulsada\%20M\%20PhD.pdf

[8] Chaparro, A. and Cetegen, B. (2006). Blowoff characteristics of bluff-body stabilized conical premixed flames under upstream velocity modulation, Combustion and Flame, 144, 1-2, 318-335.

[9] Nair, S. and Muruganandam M. (2004). Lean Blowout Detection in a Single Nozzle Swirl Cup Combustor, 42nd AIAA Aerospace Sciences Meeting, 5, 138.

[10] Lieuwen, T. (2006), Chapter 3.1.1: Static and Dynamic Combustion Stablity, In: Gas Turbine Handbook. USA, Department of energy, office of fossil energy, 124-145.

[11] Noble, D. and Shareef, A. (2006) Syngas Mixture Composition Effects Upon Flashback and Blowout, ASME Conference Proceedings, 13, 357-368

[12] Sarli, V. and Bendetto, A. (2007). Laminar burning velocity of hydrogen-methane/air premixed flames," International Journal of Hydrogen Energy, 32, 5, 637-646.

[13] Mansour, M. (2012). The stabilization mechanism of highly stabilised partially premixed flames in a concentric flow conical nozzle burner, Experimental thermal and fluid science, 43, 55-62.

[14] El-Mahallawy, F. (2005). Mixing and nozzle geometry effects on flame structure and stability, Combustion Science and Technology, 2, 60-12.

[15] Baudoin, E. (2011). Effect of partial premixing on stabilization and local extinction of turbulent methane/air flames. Chia Laguna, 4, 20-35.

[16] Elbaz, M.A. (2013). An Experimental Study of the Effect of Partial Premixing Level on the Interaction between the Flame Kernel and Flow Field, Computer Science Journals, 1, 121-145.

[17] El-Mahallawy, F. (2007). Mixing and nozzle geometry effects on flame structure and stability, Combustion Science and Technology, 2, 249-263.

[18] Peters, N. (2000). Turbulent Combustion, vol.II. 1st ed., Cambridge, Cambridge University Press. United Kingdom

[19]Mansour, M. (2004) The flow field structure at the base of lifted turbulent partially premixed jet flames, Experimental Thermal and Fluid Science, 7, 771-779.

[20] Joedicke, A. (2005) The stabilization mechanism and structure of turbulent, Proceedings of the Combustion Institute, 1, 901-909.

[21] Dutt, A. (2015). Effect of Mesh Size on Finite Element Analysis of Beam, International Journal of Mechanical Engineering (SSRG-IJME), 12, 8-9.

[22] Charles, M. (2006). Comparison of Pressure-Based and Density-Based Methods for low Mach number CFD computations, 3, 12-15.

[23] Pupo, R. (2011). Adiabatic Flame Temperature for Combustion of Methane, Journal of Mathematical Modelling, 2, 3-7.

[24] Khalil, R. (2010) Effect of Pressure and Inlet Velocity on the Adiabatic Flame Temperature of a Methane-Air Flame, Jordan Journal of Mechanical and Industrial Engineering, 4, 21-28.

[25] Jonathon, Z. (2009). Modelling Fluid Flow Using Fluent,” 35-38.

[26] Mathur, M.J. (2007). A pressure-based method for unstructured meshes, Numerical Heat Transfer, Part B:

Fundamentals, 20-21.

[online] http://www.tandfonline.com/doi/pdf/10.1080/10407799708915105?needAccess=true 
[27] Salim, M. (2011). Comparison of RANS, URANS and LES in the Comparison of RANS, URANS and LES in the Prediction of Airflow and Pollutant Dispersion," the World Congress on Engineering and Computer Science, 40-43.

[28] Baudoin, E. (2012). Effect of partial premixing on stabilization and local extinction of turbulent methane/air flames, Flow Turbulence Combust, 9, 269-284.

[29] Manera, J. (2008). Kelvin-Helmholtz instabilities occurring at a nacelle exhaust," Aeroacoustics Conference, 14, 235-264.

[30] Almawali J. (2016, November). Numerical Analysis of Flame Characteristics and Stability for the Conical Nozzle Burner, Master thesis, Sheffield Hallam University. 